\title{
Mendigainera: Scaling the Peak of the Basque Library Backlog
}

\section{Marcelino Ugalde and Kathryn Etcheverria}

\begin{abstract}
The Basque Studies Collection, housed at the University of Nevada, Reno, is world-renouned as the most extensive collection of materials both by and about the Basque people. Efforts to keep pace with the cataloging backlog of this multilingual collection have met with limited success. This article describes the Basque Cataloging Project, administered from 1993 to 1996 and funded by an HEA Title II-C grant, as it worked to produce cataloging for 10,000 monographic titles. Attention is given to preparation for the project, special considerations in cataloging this unique collection, and recommendations for the future.
\end{abstract}

\section{$\mathbf{E}$} ish without a strong library collection. From its inception in 1967, the Basque Studies Program at the University of $\mathrm{Ne}$ vada, Reno, has understood the importance of building a strong Basque collection to support scholarly research activities. The foundation of the Basque Studies Library was two respectable private libraries totaling more than 4,300 works. The purchase of these libraries from Europe was facilitated by Robert Laxalt and the late Jon Bilbao. Robert Laxalt made contacts with the Veyrin family in the late 1960s, and Jon Bilbao spoke to the Goñi family in 1972 (Basque Studies Program 1983). Fortunately, the materials in these libraries complemented each other. One emphasized the northern Basques in France and the other focused on the southern Basques of Spain, especially the Navarrese region.
Collection development efforts by the Basque Library continued to flourish through annual appropriations of approximately $\$ 10,000$ from the university library's materials budget. Since 1986, the Basque Library has acquired more than 1,000 new and retrospective titles annually, receiving $2 \%$ of the library's total materials budget (Basque Studies Program 1987). In 1997, the number of new titles added reached 1,300, with almost of all of these titles going directly into an uncataloged backlog.

\section{The Growing Backlog}

Why had the backlog of the Basque collection become so large and unmanageable? A variety of factors beyond the control of the university and its Basque Studies Program may have created or contributed to the situation, including

MaRCELINo UGaLde (ugalde@unr.edu) is Basque Studies Librarian, University of Nevada, Reno. Kathryn Etcheverria (kathryne@unredu) is Basque Catalog Librarian, University of Nevada, Reno. Manuscript received January 9, 1998; accepted for publication April 14, 1998. 
publishing trends in the Basque country, limited efforts related to international cooperation in cataloging, and the consequent lack of catalog copy for foreign monographs in the format usable by American libraries.

While publishing may have stabilized or declined among other linguistic or ethnic groups, literature published in the Basque provinces in monographic form has experienced a boom in recent years. Otero-Boisvert (1992) points out that the Basque culture, long suppressed under the Franco regime, just recently began producing more public evidence of a written culture and literature, while other cultures were already under the strong influence of a well-established publishing industry. After Franco's death, publication in the Basque language became a political statement made by those with nationalistic and linguistic enthusiasm for the Basque homeland. This, coupled with a dramatic increase in the learning of the Basque language by the young people of that region, may have been influential in creating a $63.5 \%$ increase in new Basque language publications in 1985.

In an effort to keep pace with this publishing boom, librarians at the University of Nevada, Reno, responded with an ambitious acquisitions program. The library's policy was to acquire virtually everything published by and about Basque people. The size of its monographic collection grew from 13,997 titles in 1980 to 25,642 titles in 1990 , an average annual increase of approximately $10 \%$ during those years.

The University of Nevada, Reno Library, along with other academic and special libraries, was unable to acquire the quality and quantity of catalog records representing foreign language monographs that are usually available for domestic academic titles. The problem is well documented. Grover (1991) found in his 1983-1985 study that although Latin American materials were widely acquired by large academic and public libraries, adequate cataloging for the materials was often not provided. Results of the study of bibliographic control by Leazer and
Rohdy (1995) lend support to the theory that far less control exists over foreign monographs than domestic monographs; moreover, bibliographic records available for foreign monographs tend to be lower quality than those of monographs in general (Sercan 1994). Further, the availability of cataloging for these foreign titles may be on the decline. Sercan (1994) found, with regard specifically to Latin American publications searched in the RLIN database, a marked decline in available catalog copy compared to Grover (1991).

One possible reason behind the lack of catalog copy for foreign monographs is the slowdown of once ambitious efforts to achieve international cooperation in cataloging. Lambrecht (1995) points out that massive efforts in the 1960 s to provide an international standard for bibliographic description have not been significantly helpful beyond the English-speaking world, nor have they moved far beyond publication of the Anglo-American Cataloguing Rules. Access by academic libraries to the national bibliographies of other countries is only minimally helpful when a lack of standardization of computer formats creates not-easily-transferred electronic versions of records that necessitate inefficient rekeying of cataloging records of other nations and languages. For example, in the case of the Basque Library, where approximately $60 \%$ of its collection is published in Spain, a tool with limited usefulness has been the Bibliografía Nacional Española. Nonetheless, beyond the need to translate subject headings and portions of other access points, the real problem in using matching records is that they are not transferable.

Similar to findings in the literature, a sample search performed prior to the project resulted in a low hit rate, only $40 \%$ of sample titles searched (see table 1). Relatively few were Library of Congress (LC) records, the rest being member copy. Clearly, a cataloging project that would address the needs of this unique collection would include provision for professional 
TABLE 1

Preproject Sample Search Results

\begin{tabular}{lcccc}
\hline \hline Type of OCLC Record & Classes D, E, F & Class P & Basque Language & \multicolumn{1}{c}{ Total } \\
\hline DLC & $22 / 20 \%$ & $19 / 12 \%$ & $6 / 6.5 \%$ & $47 / 13 \%$ \\
Member & $40 / 36 \%$ & $49 / 32 \%$ & $6 / 6.5 \%$ & $95 / 27 \%$ \\
Total found & $62 / 56 \%$ & $68 / 44 \%$ & $12 / 13 \%$ & $112 / 40 \%$ \\
No match & $49 / 44 \%$ & $85 / 56 \%$ & $78 / 87 \%$ & $212 / 60 \%$ \\
Total & $111 / 100 \%$ & $153 / 100 \%$ & $90 / 100 \%$ & $354 / 100 \%$
\end{tabular}

staff skilled in original cataloging in a multilingual environment, as well as classified staff with the ability to work with a high percentage of member records, which often require additional time to add LC call numbers and subject headings.

Searching tracked during the course of the cataloging project resulted in slightly higher hit rates than those shown in the prior random sample (overall hit rate $40 \%$ ), but low enough to justify the staffing needs described above.

\section{EARLY EFForts to Catalog the Collection}

Providing bibliographic access for this multilingual collection has always been a challenge. Despite all efforts and good intentions of the technical services staff in the main library, a backlog of uncataloged books began to grow. The growth was occasionally slowed by the outstanding efforts of university catalogers. However, the nonstop rigors of title search and verification in three different foreign languages-Basque, Spanish, and French-along with the other problems associated with acquiring materials from foreign sources and getting them cataloged, demanded more time and effort than the technical services staff could supply.

In order to provide access to the collection, a bibliographer handled local processing and assigned call numbers for the material. He adapted from the LC classification system temporary call numbers using the classification number portion and then added either the au- thor's name or a significant word from the title. He was assisted in the local proccessing of various material formats for many years by students and classified staff.

In 1983, two catalogers were hired for a year through funding from the Basque Autonomous Government in Spain to achieve as much cataloging as possible. After one full year of hard work, a significant portion of the Basque Library received full-level access. It would be eleven years before another serious effort was made to reduce the tremendous backlog of Basque material.

\section{A Cataloging Grant}

In late 1993, the University of Nevada, Reno Library initiated a cataloging project intended to eliminate part or all of the backlog for the Basque Library. Funded by a grant from the Department of Education (an HEA Title II-C grant), the university hired a project director, two catalogers, three classified staff, and student workers. The primary focus would be to catalog 10,000 monographs in the Basque Studies Library. It was anticipated that the project staff would, in a period of two years, produce more than 10,000 bibliographic records by creating original catalog copy or by editing existing full-level MAchine Readable Cataloging (MARC) records.

Other objectives included completion of related authority work and promotion of increased use of the newly cataloged titles and the collection as a whole within the Basque scholarly community. 
Language Training

The probability of hiring catalog librarians with the necessary skills in the Basque language was predicted to be very slim, and such turned out to be the case. The length of the project did not allow enough time for the catalogers to learn the language to the extent desired, but training was tailored to make them bibliographically proficient.

It is one thing to do descriptive cataloging in a language in which you do not have the slightest understanding, but it is another thing entirely to classify and provide subject analysis. Knowing that catalogers with sufficient Basque language proficiency were nonexistent, the Basque Studies staff went to work preparing cataloging tools, such as a trilingual guide (Basque, English, and Spanish) to publishing terms, common European publisher names and locations, cardinal and ordinal number translations, and title page convention descriptions. Additional tools included a photocopy of a name authority list of Basque authors, with pseudonyms produced by the International Society of Basque Studies, and a photocopy of the section about Basque from Allen (1975), which presented a grammatical structure and background for the language.

A two-week intensive language training session began as soon as the cataloging staff arrived. The focus of the two-week sessions was to discuss the handouts and to produce some sample cataloging for a variety of works: current publications, older backlog monographs, and rare book titles. The catalogers quickly became aware of the differences between a non-Indo-European language (Basque) and Indo-European languages (Spanish, French, English). After the two-week training, the instructors made arrangements to meet with the cataloging project staff two hours weekly or when needed to answer questions and solve problems during the first year of the cataloging project. During the remaining term of the project, language assistance was provided to the cataloging staff when necessary, usually a few times a week.
Bibliographic control in European literature is reasonably comprehensive. From Spain, the Biblioteca Nacional de España distributes its national bibliography of cataloged items submitted for legal deposit since 1976 in the Bibliografia Nacional Española, distributed by ChadwickHealey on CD-ROM. Because the preponderance of the Basque collection is published in Spain, whether in Spanish or Basque language, the purchase and use of this CD-ROM version was considered well worth both the time spent searching for records and the money spent. In a sample taken from monographs cataloged from June 1995 through August 1995, 41.5\% of original records had a Bibliografía Española record available. Particularly useful were entries for personal, corporate, and series names. Further, Spanish language subject headings were used as a guide to content and sped up the process of assigning LC subject headings. Because IBERMARC catalog records are read-only and not transferable to the PRISM Catme software, all data had to be keyed.

\section{Descriptive Cataloging}

Beyond the apparent challenge of gaining some familiarity with a non-Romance language, catalogers grappled with stylistic idiosyncrasies found in Basque language publishing. Modern printers often make use of the Basque typeface on title pages and introductory material. It is believed that this unique face was developed by Basque carpenters during the Middle Ages, but really became widely used in the twentieth century (North American Basque Organization 1997, 3). Use of the typeface became associated with the interest in Basque nationalism. Examples of the face are shown in figure 1 .

\section{TOMBE BISAYE PTR L CoLAs}

\section{EL PAIS VISCO POR CARLOS ESPEL VRINGI $Y$ VICTOR MRINI GIITIRRO}

\section{EYSKIL IPYRKAK}

Figure 1. Examples of the Basque typeface. 
Characteristic in the Basque font is consistent capitalization of all the words on the title page, while common usage in Basque calls for the same rules of capitalization as in Spanish and French. This exasperating style, combined with the highly synthetic and post-positional nature of the language, makes the title page and cover of a Basque publication sometimes appear as an unlocked puzzle. Without some knowledge of Basque vocabulary, grammar, and syntax, Basque on the title page is nearly indecipherable.

Interestingly enough, the Basque language is free of diacritics. Other languages commonly used in and around the Basque culture and found in the collection, such as French and Spanish, are not. Those at work cataloging these materials familiarize themselves with both key equivalents for PCs using Passport/PRISM/Catme plus software, as well as the three-digit numerical codes representing diacritics common to those languages, which display in curly brackets in place of the diacritic in the Innovative Interfaces system display.

\section{AUTHORITY WORK}

Name authority, particularly in a multilingual environment, always presents challenges for catalogers. LC has led the way in many cases by establishing names with a preference for the Castilian spelling of names over the Basque spelling. Recent agreements, however, grant the Basque language co-official status with Castilian in the Basque region of Spain (País Vasco, Spain, Gobierno Vasco, SCP 1983). Now, most modern Basque writers prefer to use the Basque orthography of their names, reinforcing their cultural differences from the rest of Spain and France (see table 2).

TABLE 2

Basque Names

\begin{tabular}{lc}
\hline \hline Spanish Form & Basque Form \\
\hline Angel Lerchundi & Anjel Lertxundi \\
José Miguel & Joxe Miel \\
Domingo Aguirre & Txomin Agirre \\
Echeverria & Etxeberria
\end{tabular}

TABLE 3

Basque $W$ riters and Pseudonyms

\begin{tabular}{lc}
\hline \hline Real Name & Pseudonym \\
\hline Nikolas Ormaetxea & Orixe \\
Pierre Topet & Etchahun \\
Jose Luis Alvarez & Larresoro or \\
Enparantza & Txillardegi \\
Emilio Lopez Adan & Beltza \\
Esteban Urkiaga & Lauaxeta \\
\hline
\end{tabular}

Name authority is further complicated by the use of pseudonyms or nicknames among Basque people, a culturally embedded custom dating back to the thirteenth century, not merely used by literary figures ( $W$ hite 1992). Basque people were known by their house name rather than their sumame (Lhande 1908, 14-16; Caro Baroja 1971, 211-13; Manterola $1980,537-600$ ), a practice so pervasive that most young men did not know their surnames until they served in the military and found surnames on their military documents. Some prominent writers who are well-known by their pseudonyms are shown in table 3 .

Since 1975, pressure to publish Basque works in the unified Basque dialect, Euskara Batua, has compelled publishers to use the single Basque surname in preference over the old double Spanish surnames (White 1992, 11). Writing careers that span the two eras often require references in authority records.

\section{Tools and Resources Used by the StafF}

A valuable source in decoding and cross-referencing pseudonyms and establishing authors' dates is the monumental multivolume work, Eusko Bibliographia, compiled by Bilbao and considered the most comprehensive bibliography of Basque materials in the world. Initially, the set was 10 volumes spanning the Basque bibliographic years from the beginning of history through 1975. In 1985, a three-volume supplement was published by the Basque University Press, covering the years 1976-1980. From 1987 to 1991, a bulletin was irregularly published, organizing information from 
DECHEPARE， BERNARDUM

Lingvae Vasconvm Primitiae per Dominum Bernardum Dechepare Rectorem

Sancti Michaelis Veteris. [Burdigalae: Franciscum Morpain, 1545]

(28h.).

LIZARDI, XABIER (seudónimo de Aguirre, José María).

PELOTA (General)

Acker, P.: "Fronton Basque," Echo de Pairs, 1904 (JL.25).

Adema, G.: Notice sur le jeu de paume au rebot, jeu national de

Basques. Bayonne, 1894.

Figure 2. Examples from Eusko Bibliographia.

1987 to 1989 as a means for the Association of Basque Bibliography to keep current with Basque bibliography. Recently, the Basque University Press has completed a second supplement to Eusko Bibliographia, listing entries for the years 1980-1985. Bilbao dedicated most of his life to Basque bibliography, traveling extensively throughout his lifetime and recording entries for monographs, serials, pamphlets, leaflets, journal articles, government documents, and manuscripts. Basically, everything by and about Basques has been included. Bibliographic entries were organized by the standard author, title, subject, and series titles format. All entries were interfiled and alphabetized. Subject headings were developed using Spanish subject headings, including place names, mostly as a sign of the time period Bilbao was working in, during the Franco dictatorship. Sample entries are shown in figure 2 .

The benefits of having access to this multivolume masterpiece were numerous. On many occasions the bibliography helped the catalogers in name authority work to link surnames when only authors' pseudonyms were present; in addition, it helped in establishing dates for certain authors.

A list that focuses strictly on pseudonyms for literary figures is Entrasaca de un diccionario de seudonimos by Amezaga (1991). Though dated, the list, giving author, profession, century author flourished, and corresponding pseudonym or pseudonyms, is reliable.

Place names pose another problem area for the Basque region in terms of name au- thority. Although catalogers by policy choose the Spanish forms over Basque forms in names with spelling conflict, the Spanish Statute of Autonomy (1982) made the Basque language co-official with Spanish in the Basque region. Emanating from the statute, an authoritative list of place names, Euskal Herriko Udalen Izendegia (Euskal Herriko Autonomi Elkartearen Administrazio Orokorra, HABE 1993), reveals that the Basque form of a name became official about as often as the Spanish form. Catalogers referred to this list frequently.

Another useful source to aid in deciphering title page and prefatory material was A Manual of European Languages for Librarians (1975). The chapter on the Basque language offers specific information on grammar, syntax, surnames, and what to expect on the title page, followed by a glossary of publishing terms.

\section{SHELFLISTING}

As with many special collections, the shelflist of the Basque collection shows signs of considerable effort to fit material into portions of the schedules not fully developed by LC. These efforts are most evident in Basque literature, history, and geographic description and travel. In December 1995, very close to completion of the Basque Cataloging Project, a survey of the Basque collection shelflist showed that in DP402, for example, signifying Spain, local history and description, other cities, towns, etc., 84 out of the existing 220 Cutter numbers had been created locally. Similarly, in the literature sched- 
ule, where PH5339 represents all works of literature by individual Basque authors, an impressive 195 out of 308 authors represented in the UNR online catalog (WolfPAC) were established at the University of Nevada, Reno.

Beyond published sources, project catalogers had exclusive access to a number of useful documents. "Language information: English, Spanish, Basque" was compiled specifically for the project staff by the Basque Studies Department. It was a quick reference tool that pulled together such information as publishing terms, grammar, syntax, and major publishing houses whose works were found most frequently in the collection.

\section{A Successful Conclusion. . . . WHAT IS IN STORE?}

As of February 29, 1996, the closing date for the project, staff had produced 3,425 DLC records, 2,824 member copy records, and 4,261 original catalog records, for a total of 10,510 catalog records, representing $40 \%$ of the total cataloged monograph holdings for the Basque collection. More than 3,100 authority records were either created or exported to support corresponding new bibliographic records in the university's online catalog. The production goals of the Basque Cataloging Project were met and exceeded.

Newly cataloged titles were primarily promoted via the online catalog. Efforts to inform Basque scholars were made through the BSP Newsletter published biannually. Further ease of access was achieved when the University of Nevada made the online catalog available via the World Wide Web.

When the cataloging project ended, a period of roughly one year passed when nearly nothing was cataloged, despite an average of 84 new titles arriving monthly. The main cataloging department was not able to produce original cataloging or even maintain records for the Basque Studies Library. Consequently, the Basque backlog began to grow rapidly as was the case before the cataloging project. The backlog was and continues to be an issue. The cata$\log$ project was, without question, success- ful in meeting its goals, but followup in the form of continued maintenance and sustained cataloging for the Basque collection is paramount to ward off huge backlogs of uncataloged material.

Also important to reducing backlogs for this special collection, as well as other special collections, is a fresh attitude about cataloging from catalogers. We may need to discard the ideal of "perfect" cataloging to conquer a backlog. Along with an altered ideal, catalogers could save precious time by becoming more accepting of cataloging from other institutions. When editing the valuable few member records available, catalogers for this and other special collections do well to set a specific ceiling on the amount of time they will expend on editing records.

Reflection on this project also produced some thoughts on successful staffing. First, project staff were well suited to their task once language orientation took place. One might believe that being proficient in a language is necessary to catalog in that language, but cataloging experience and demonstrated language ability of some kind might be sufficient. Administrators were pleased with the level of language ability catalog staff held once the project was up and running, and additional language assistance was available when needed. Less than satisfactory, however, was the configuration of staff. With such a low hit-rate of OCLC Online Computer Library Center, Inc. records against the collection, hiring of one additional cataloger would have yielded better results, i.e., more original cataloging produced. Similar projects would benefit from being sure to have sufficient professional catalogers to produce cataloging for a special language collection.

In the future, adequate bibliographic access to Basque materials will continue only when cooperative efforts are established between institutions. The University of Nevada, Reno Library supplies the majority of bibliographic cataloging records of Basque language material to OCLC. Because eight to ten foreign libraries as well as a handful of U.S. academic libraries collect titles on Basque subjects, cooperative cataloging might be the answer to 
keeping up-to-date with new Basque language material, as well as reducing the backlog. A cooperative cataloging plan could create more bibliographic records for other institutions to use selectively and reduce duplication of international cataloging efforts (Byrd 1993)

There is no Basque studies collection in the United States as comprehensive as the one at the University of Nevada, Reno. Fortunately, there is an institution in the Basque country of northern Spain, the library of the Sancho el Sabio Foundation, that manages a strong Basque collection that is similar to and slightly larger than the Basque collection at the University of Nevada, Reno. Unfortunately, Sancho el Sabio uses IBERMARC, the MARC format developed by the Spanish state and adopted by the Basque country as well as the rest of Spain, which differs enough from USMARC or UNIMARC to prevent IBERMARC catalog records from being converted to the UNIMARC format for OCLC. Further, OCLC has decided to stop allocating time and resources to developing software to convert various MARC versions to UNIMARC. At the present time, institutions in the Basque country are not willing to invest time or resources to convert their catalog records to the UNIMARC format. This dilemma could leave the Basque Studies Library in an unfortunate position for providing adequate access to its collection in the future.

More serious work on cooperation between cataloging agencies at the international level is paramount. The benefits of cooperation will be realized by all if we persist with the vision that a work should be cataloged only once in its country of publication and consequently for the rest of the world (Lambrecht 1995). In the future, the Basque Studies Library will have to rely on cooperation and collaboration, instead of grants and other funding sources, to sustain its cataloging needs.

\section{Works Cited}

Allen, C. G. 1975, Basque, In A manual of European languages for librarians, 774-99. London, New York: Bowker.

Amezaga, Elias. 1991. Entresaca de un diccionario de seudonimos Revista internacional de los estudios vascos 36: 413-26.

Basque Studies Program, University of Nevada, Reno. 1983. The Basque Studies Program, 1967-1982. Basque studies program newsletter 27(May): 3-8

Basque Studies Program, University of Nevada, Reno. 1987. The Basque Studies Program, 1982-1987. Basque studies program newsletter 36 (November): $3-5$.

Bilbao, Jon. 1970. Eusko bibliographia. 10 vols. San Sebastián: Editorial Auñamendi, Estornes Lasa Hnos.

Byrd, Jacqueline. 1993. A cooperative cataloging proposal for Slavic and East European languages and the languages of the former Soviet Union. Cataloging \& classification quarterly 17: 87-96.

Caro Baroja, Julio. 1971. Los vascos, Madrid: Ediciones ISTMO.

Etcheverria, Kathryn. 1996. Basque Studies collection cataloging project final performance report, HEA Title IIC, P.L. 89-329. Reno: University of Nevada, University Libraries.

Euskal Herriko Autonomi Elkartearen Administrazio Orokorra, HABE. 1993. Euskal Herriko Udalen Izendegia In 1994 Agenda, 32-42. Donostia: HABE.

Grover, Mark L. 1991. Cooperative cataloging of Latin American books: The unfulfilled promise. Library resources \& technical services 35 : 406-15.

Joachim, Martin D. 1993. Issues and problems in cataloging the languages of the world. In Languages of the world: Cataloging issues and problems, ed. Martin D. Joachim, 1-14. New York: Haworth Pr.

Lambrecht, Jay H. 1995. International cooperation in cataloging: Progress and constraints. In Advances in librarianship, vol. 19, ed. Irene Godden, 217-.38, San Diego: Academic Pr.

Leazer, Gregory H., and Margaret Rohdy. 1995. The bibliographic control of foreign monographs: A review and baseline study. Library resources b technical services 39 29-42.

Lhande, Pierre 1908, Autour d'un foyer basque: Récits et idées. Paris: Nouvelle Librairie Nationale.

Manterola, Ander 1980. Etxea In Euskaldunak: La etnia tasca, vol. 3, ed. José Miguel de Barandiarán, 537-600. San Sebastián: Etor.

North American Basque Organization. 1997. Hizketa (Spring)7: 3 .

Otero-Boisvert, Maria. 1992. The publishing industry in the Basque Country: An introduc- 
tion. In Euro-librarianship: Shared resources, shared responsibilities, pt. 1, ed. Assunta Pisani, 155-71. New York: Haworth Pr.

País Vasco, Spain. Gobierno Vasco, Servicio Central de Publicaciones, 1983, Euskal herriko autonomia estatutoa. Gasteiz: Gobierno Vasco, Servicio Central de Publicaciones.

Sercan, Cecilia S 1994. Where has all the copy gone? Latin American imprints in the
RLIN database, Library resources \& technical services 38: 56-59.

Tovar, Antonio. 1957. The Basque language (translated by Herbert Houghton). Philadelphia: University of Pennsylvania Pr.

Walter, Michael, 1993. Central Asian cataloging: Problems and prospects. Cataloging $d$ classification quarterly 17: 149-57.

White, Linda 1992. Basque on the title page. Paper presented at SALALM Conference, June 3.

\section{STATEMENT OF OWNERSHIP AND MANAGEMENT}

Library Resources \& Technical Services, Publication No. $311-960$ is published quarterly (April, July, October, and January) by the Association for Library Collections and Technical Services, American Library Association, 50 E. Huron St., Chicago, IL 60611-2795. Annual subscription price, \$27.50. American Library Association, 50 E. Huron St., Chicago, IL 60611-2795, owner; Association for Library Collections and Technical Services, American Library Association, 50 E. Huron St, Chicago, IL 60611-2795, publisher; Jennifer Younger, 221 Theodore M. Hesburgh Library, University of Notre Dame, Notre Dame, IN 46556-5629, editor. Periodicals postage paid at Chicago, Illinois. Printed in U.S.A. As a nomprofit organization authorized to mail at special rates (Section 423-12, Domestic Mail Manual), the purpose, function, and nonprofit status of this organization and the exempt status for federal income tax purposes have not changed during the preceding twelve months.

\section{EXTENT AND NATURE OF CIRCULATION}

("Average" figures denote the average number of copies printed each issue during the preceding twelve months; "Actual" figures denote actual number of copies of single issue published nearest to filing date-April 1998 issue.) Total number of copies printed: Average, 7,245; Actual, 7,440. Paid and/or requested circulation: not applicable (i.e, no sales through dealers and carriers, street vendors, and counter sales). Mail subscription: Average, 6,577; Actual, 6,695. Total paid and/or requested circulation: Average, 6,577; Actual, 6,695. Free distribution by mail, carrier, or other means, samples, complimentary, and other free copies: Average, 66; Actual, 68. Total distribution: Average, 7,245; Actual, 7,440. Copies not distributed: office use, leftover, unaccounted, spoiled after printing: Average, 602; Actual, 677. Returns from neus agents: Not applicable. Total (sum plus precious three entries): Average, 7,2450; Actual, 7,440. 